\title{
Diagnosis-specific WBRT-30-CRC Score for Estimating Survival of Patients Irradiated for Brain Metastases from Colorectal Cancer
}

\author{
DIRK RADES ${ }^{1}$, HEINKE C. HANSEN ${ }^{1}$, STEFAN JANSSEN ${ }^{1,2}$, STEVEN E. SCHILD ${ }^{3}$ \\ ${ }^{1}$ Department of Radiation Oncology, University of Lübeck, Lübeck, Germany; \\ ${ }^{2}$ Medical Practice for Radiotherapy and Radiation Oncology, Hannover, Germany; \\ ${ }^{3}$ Department of Radiation Oncology, Mayo Clinic, Scottsdale, AZ, U.S.A.
}

\begin{abstract}
Background/Aim: Existing survival scores for patients with brain metastases were created in heterogeneously treated cohorts. A new score was developed in 56 patients with brain metastases from colorectal cancer treated with $10 \times 3 \mathrm{~Gy}$ of whole-brain radiotherapy (WBRT). Patients and Methods: Factors found significantly associated with survival $(p<0.05)$ or showing a trend $(p<0.08)$ were included in the tool. The new WBRT-30-CRC was compared to diagnosis-specific graded prognostic assessment (DS-GPA) classification for gastrointestinal cancers. Results: The WBRT-30-CRC included four prognostic groups: 3-4, 5-6, 7-9 and 10 points. Six-month survival rates were $0 \%, 15 \%, 38 \%$ and $80 \%$. PPV of the 3-4 points-group predicting death $\leq 6$ months was $100 \%$ (91\% for DS-GPA of 0.0-1.0). PPV of the 10 points-group predicting survival $\geq 6$ months was $80 \%$ (0\% DS-GPA of 3.5-4.0, 33\% DSGPA of 3.0-4.0). Conclusion: The WBRT-30-CRC appeared very precise in identifying patients with brain metastases from colorectal cancer dying $\leq 6$ months or surviving $\geq 6$ months.
\end{abstract}

Brain metastases are relatively common and occur in $20-40 \%$ of adult cancer patients during their malignant disease (1). Despite the fact that radiosurgery and fractionated stereotactic radiotherapy have become more popular during recent years, many patients with brain metastases receive whole-brain radiotherapy (WBRT) alone, particularly those with more than three lesions, significant comorbidities, or poor

This article is freely accessible online.

Correspondence to: Prof. Dirk Rades, MD, Department of Radiation Oncology, University of Lübeck, Lübeck, Ratzeburger Allee 160, 23562 Lübeck, Germany. Tel: +49 451 50045401, Fax: +49 45150045404, e-mail: dirk.rades@uksh.de

Key Words: Brain metastases, whole-brain radiotherapy, 30 Gy in 10 fractions, survival, scoring system, colorectal cancer. performance scores. Different WBRT regimens are available including 20 Gy in 5 fractions, 30 Gy in 10 fractions and 40 Gy in 20 fractions. Twenty Gy in 5 fractions is similarly effective when compared to $30 \mathrm{~Gy}$ in 10 fractions in patients with more than three lesions and limited survival prognoses (2). However, the risk of WBRT-related neurocognitive decline increases with the dose per fraction (3). Thus, $20 \mathrm{~Gy}$ in 5 fractions is most appropriate for patients with very poor survival prognoses who are unlikely to live long enough to develop neurocognitive deficits.

Patients with longer expected survival likely benefit from WBRT with higher total doses and lower doses per fraction because of improved intracerebral control, overall survival, and neurocognitive function $(3,4)$. The risk of neurocognitive deficits after WBRT can be further reduced with hippocampus sparing $(5,6)$. Therefore, it is very important to predict a patient's survival time to optimally individualize the treatment.

Several scoring systems mainly focusing on WBRT were developed to facilitate such prediction (7-10). The highest positive predictive values to identify patients dying within 6 months after WBRT and patients surviving for at least 6 months were found for the WBRT-30 score, which was developed in a more homogeneously treated cohort of patients than other scoring systems such as the recursive partitioning analysis (RPA) classification, our preceding scoring system including different WBRT-regimens, and the graded prognostic assessment (GPA) classifications (7-10). In the WBRT-30 score, all patients received WBRT alone with 30 Gy in 10 fractions, the most common WBRT regimen worldwide (10). To account for the different biology of the primary tumor types associated with brain metastases and provide the best personalized treatment, diagnosis-specific GPA classifications (DS-GPA) were developed including a DS-GPA for gastrointestinal cancers (11). However, gastrointestinal cancers include esophageal cancer, gastric cancer, colorectal cancer and other tumor entities that differ regarding their biological behavior. Therefore, it appears reasonable to develop an even 
more specific tool. Therefore, the present study was performed to create the WBRT-30-CRC score specifically for patients with brain metastases from colorectal cancer.

\section{Patients and Methods}

The data of 56 patients treated with $10 \times 3$ Gy of WBRT without additional local therapies for brain metastases from colorectal cancer between 1998 and 2017 were retrospectively evaluated with respect to survival, particularly survival at 6 months. All patients treated with WBRT alone for brain metastases were considered eligible. The data were obtained from patient files and an existing database currently including a total of 2,779 patients irradiated for brain metatsases. This patient cohort represents a series of patients who were assigned to WBRT alone because they had a KPS $<60 \%$, significant co-morbidities, significant extracranial metastatic spread or multiple intracerebral lesions. $30 \mathrm{~Gy}$ in 10 fractions was the institutional standard WBRT-regimen for many years. Patients were followed until death or for a least 6 months following WBRT.

Initially, the eight potential predictors of survival that were available for all 56 patients were analyzed (Table I). Median values were used for creation of the compared subgroups of each potential predictor. The eight potential predictors included controlled primary tumor (no $v s$. yes), interval between the first diagnosis of colorectal cancer and start of WBRT ( $\leq 26 v s .>26$ months, median interval=26 months), systemic treatment prior to WBRT (no $v s$. yes), age at WBRT ( $\leq 69 v s .>69$ years, median age $=69$ years), gender, Karnofsky performance score (KPS) $(\leq 70 \%$ vs. $>70 \%$, median $=70 \%$, number of brain metastases (1-3 vs. $\geq 4$, median number=3), extracranial spread at the start of WBRT (no vs. yes). For survival analyses, the Kaplan-Meier method and the log-rank test were used. Those factors that were found significant $(p<0.05)$ or showed a trend $(p<0.08)$ were included in the WBRT-30-CRC. The 6-month survival rates of the included factors were divided by 10 (=factor scores). Subsequently, the factor scores were summed up for each patient to obtain the patient scores. Based on the patient scores, prognostic groups with different 6-month survival probabilities were created.

Additionally, the WBRT-30-CRC was compared to another diagnosis-specific score, the DS-GPA for gastrointestinal cancers regarding the positive predictive values (PPV) of the least favorable prognostic group (correct prediction of death within 6 months after WBRT), and the most favorable group (correct prediction of survival for at least 6 months after WBRT. In the DS-GPA for gastrointestinal cancers, the KPS was the only factor considered (11). Based on KPS, the DS-GPA included four prognostic groups, i.e. $0.0-1.0,1.5-2.5,3.03 .5-4.0$. The corresponding KPS were $\leq 70 \%$ (GPA 0.0-1.0), 80\% (GPA 1.5-2.5), 90\% (GPA 3.0) and 100\% (GPA $3.5-4.0$ ), respectively. In addition, pairwise comparisons of the prognostic groups (WBRT-30-CRC and DS-GPA) were performed for both scoring systems (Chi-square test).

\section{Results}

The results of the survival analysis are summarized in Table II. Improved survival was significantly associated with KPS $>70 \%$ ( $p=0.002)$. In addition, a longer interval (>26 months) between diagnosis of colorectal cancer and WBRT $(p=0.064)$ and presence of only 1-3 brain metastases $(p=0.073)$ showed
Table I. Distribution of the investigated potential predictors of survival.

\begin{tabular}{lc}
\hline Potential predictor & $\begin{array}{c}\text { N patients } \\
(\%)\end{array}$ \\
& \\
Controlled primary tumor & $11(20)$ \\
No & $45(80)$ \\
Yes & \\
Interval from first diagnosis of & \\
colorectal cancer to WBRT & $29(52)$ \\
$\leq 26$ months & $27(48)$ \\
$>26$ months & \\
Systemic treatment prior to WBRT & $16(29)$ \\
No & $40(71)$ \\
Yes & \\
Age & $29(52)$ \\
$\leq 69$ years & $27(48)$ \\
$>69$ years & \\
Gender & $27(48)$ \\
Female & $29(52)$ \\
Male & \\
Karnofsky Performance Score & $44(79)$ \\
$\leq 70 \%$ & $12(21)$ \\
$>70 \%$ & \\
Number of brain metastases & $30(54)$ \\
$1-3$ & $26(46)$ \\
$\geq 4$ & \\
Extracranial metastases & $9(16)$ \\
No & $47(84)$ \\
Yes &
\end{tabular}

strong trends. The 6-month survival rates of these three predictive factors were used to create the diagnosis-specific WBRT-30 score (Table III). Patient scores between 3 and 10 points were obtained (Figure 1). Based on the patients scores, four prognostic groups were created, i.e. 3-4 points $(n=23), 5-$ 6 points $(n=20), 7-9$ points $(n=8)$ and 10 points $(n=5)$. The corresponding 6-month survival rates were $0 \%(0 / 23), 15 \%$ (3/20), 38\% (3/8) and 80\% (4/5), respectively (Figure 2).

The PPV of the least favorable prognostic group (3-4 points) of the present study to correctly predict death within 6 months after WBRT was $100 \%$ compared to $91 \%$ for a DSGPA score of 0.0-1.0 (11). The PPV of the most favorable prognostic group (10 points) of the present study to correctly predict survival for at least 6 months was $80 \%$ compared to $0 \%$ for a DS-GPA score of $3.5-4.0$ and $33 \%$ for a DS-GPA of 3.0-4.0 (11).

Regarding the WBRT-30-CRC, the difference between the 3-4 points group and the 5-6 points group showed a strong trend $(p=0.064)$; differences between 5-6 points and 7-9 points groups $(p=0.24)$ and between $7-9$ points and 10 points $(p=0.31)$ groups were not significant. Regarding the DSGPA score, the difference between the 0-1.0 points group and the 1.5-2.5 points group was significant $(p=0.002)$; differences between $1.5-2.5$ points and 3.0 points groups 
Table II. Survival analyses.

\begin{tabular}{|c|c|c|c|c|c|}
\hline & $\begin{array}{c}\text { Survival at } \\
3 \text { months (\%) }\end{array}$ & $\begin{array}{c}\text { Survival at } \\
6 \text { months (\%) }\end{array}$ & $\begin{array}{c}\text { Survival at } \\
9 \text { months }(\%)\end{array}$ & $\begin{array}{c}\text { Survival at } \\
12 \text { months }(\%)\end{array}$ & $p$-Value \\
\hline \multicolumn{6}{|c|}{ Controlled primary tumor } \\
\hline No & 18 & 9 & 9 & 9 & \\
\hline Yes & 36 & 20 & 20 & 14 & 0.22 \\
\hline \multicolumn{6}{|c|}{ Interval from first diagnosis of colorectal cancer to WBRT } \\
\hline$\leq 26$ months & 17 & 7 & 7 & 3 & \\
\hline$>26$ months & 48 & 30 & 30 & 25 & 0.064 \\
\hline \multicolumn{6}{|c|}{ Systemic treatment prior to WBRT } \\
\hline No & 31 & 19 & 19 & 19 & \\
\hline Yes & 33 & 18 & 18 & 11 & 0.66 \\
\hline \multicolumn{6}{|l|}{ Age } \\
\hline$\leq 69$ years & 41 & 21 & 21 & 16 & \\
\hline$>69$ years & 22 & 15 & 15 & 11 & 0.15 \\
\hline \multicolumn{6}{|l|}{ Gender } \\
\hline Female & 33 & 19 & 19 & 19 & \\
\hline Male & 31 & 17 & 17 & 0 & 0.48 \\
\hline \multicolumn{6}{|c|}{ Karnofsky Performance Score } \\
\hline$\leq 70 \%$ & 23 & 9 & 9 & 5 & \\
\hline$>70 \%$ & 67 & 50 & 50 & 40 & 0.002 \\
\hline \multicolumn{6}{|c|}{ Number of brain metastases } \\
\hline $1-3$ & 43 & 23 & 23 & 20 & \\
\hline$\geq 4$ & 19 & 12 & 12 & 0 & 0.073 \\
\hline \multicolumn{6}{|c|}{ Extracranial metastases } \\
\hline No & 56 & 22 & 22 & 22 & \\
\hline Yes & 28 & 17 & 17 & 11 & 0.12 \\
\hline Entire cohort & 32 & 18 & 18 & 13 & \\
\hline
\end{tabular}

Bold values indicate significant $p$-values and $p$-values representing a trend.

$(p=0.92)$ and between 3.0 points and 3.5-4.0 $(p=0.51)$ groups were not significant. When looking at the most extreme (worst and best) groups, the difference between 3-4 points and the 10 points groups of the WBRT-30-CRC was highly significant $(p<0.001)$, whereas the difference between $0-1-0$ and 3.5-4.0 points groups was not significant $(p=0.75)$.

\section{Discussion}

Brain metastases are common in adult cancer patients and often associated with poor prognoses $(1,12-17)$. Treatment outcomes can be improved with modern high-precision radiotherapy, less invasive neurosurgical techniques and new systemic agents. Another concept of improving outcomes is the personalization of treatment. To most efficiently tailor the treatment regimen to a patient's specific situation, the remaining lifespan should be taken into consideration. If a patient receives WBRT, the dose-fractionation regimen should be adapted to this individual's survival prognosis. It is generally agreed that for patients with a short remaining lifespan, a short course of WBRT such as 20 Gy in 5 fractions within 1 week appears preferable, because this regimen was reported to be not inferior to longer-course programs in terms of intracerebral control and
Table III. Six-month survival rates of the factors included in the WBRT30 score for brain metastases from colorectal cancer and the corresponding factor scores.

\begin{tabular}{lcc}
\hline & $\begin{array}{c}\text { Survival at } \\
6 \text { months }(\%)\end{array}$ & $\begin{array}{c}\text { Factor } \\
\text { score }\end{array}$ \\
\hline $\begin{array}{l}\text { Interval from first diagnosis of } \\
\text { colorectal cancer to WBRT }\end{array}$ & & \\
$\quad \leq 26$ months & 7 & 1 \\
$>26$ months & 30 & 3 \\
Karnofsky Performance Score & 9 & \\
$\quad \leq 70 \%$ & 50 & 5 \\
$>70 \%$ & 23 & \\
Number of brain metastases & 12 & 2 \\
$1-3$ & & 1 \\
$\geq 4$ & & \\
\hline
\end{tabular}

survival $(1,2)$. When using such a regimen one should be aware that the risk of WBRT-related late morbidity increases with higher doses per fraction such as $4 \mathrm{~Gy}$ (3). However, since late effects can be expected only several months or even years following irradiation, patients with a very short survival time 


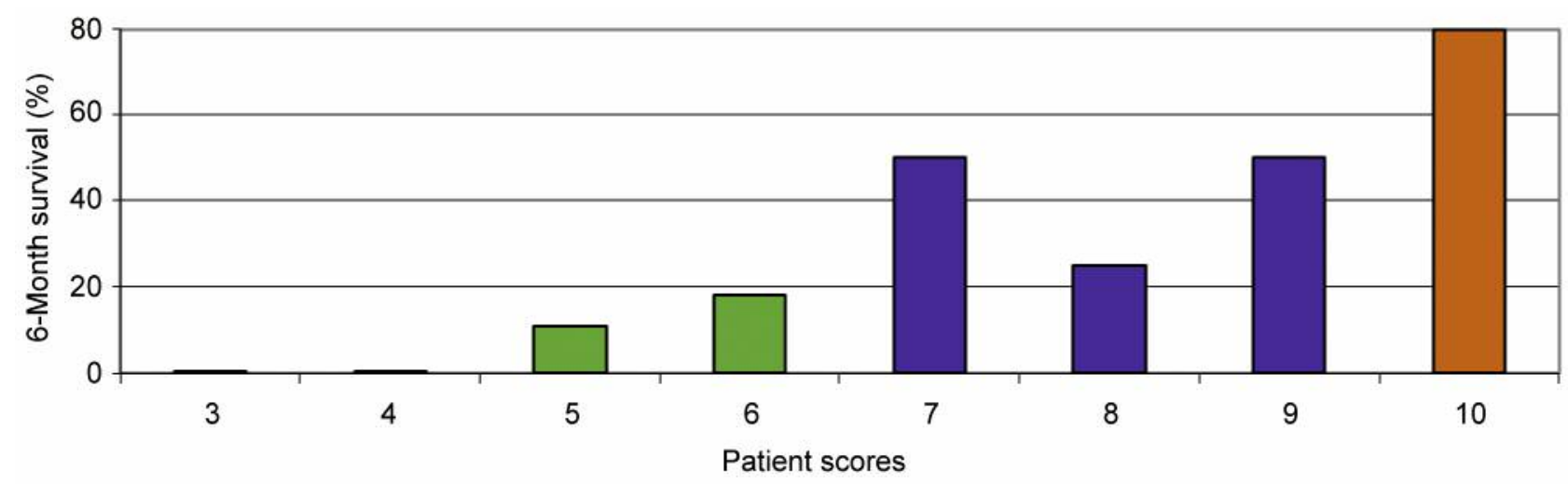

Figure 1. Scoring points for individual patients in relation to the 6-month survival rates.

are unlikely to experience such effects. In contrast, patients with a more favorable survival prognosis are at risk of developing late morbidity and should optimally be treated with doses per fraction of less than $3 \mathrm{~Gy}$ (3). To keep the risk of neuro-cognitive deficits as low as possible, the modern technique of hippocampal sparing and use of memantine should be considered as well $(5,6,19)$. Moreover, a previous study suggested that in patients with a favorable prognosis, WBRT with higher doses (e.g. $40 \mathrm{~Gy}$ in 20 fractions) resulted in improved intracerebral control and survival (4). Therefore, it is important for the treating physicians to know a patient's survival prognosis as precisely as possible to select the appropriate regimen. To address this issue, several prognostic tools were created to estimate the survival prognoses of patients with brain metastases (7-10). The first score was the RPA classification, which was developed in a heterogeneously treated cohort including several different WBRT-regimens plus/minus the addition of the radiosensitizer misonidazole or chemotherapy (7). Such heterogeneity of treatments may have introduced hidden selection biases. Another important predictive tool was the GPA classification that included four prognostic groups, GPA 0.0-1.0, GPA 1.5-2.5, GPA 3.0, and GPA 3.5-4.0 (9). Most of the patients included in the development of the GPA classification had already been used for creating the RPA classification (7). Out of the additional patients included in the GPA classification, 9\% had received a radiosurgery boost. Thus, the treatment was even more heterogeneous than for the development of the RPA classification, resulting in greater potential for bias. In our previous score, all patients received WBRT alone, but different WBRT-regimens were included (8). In order to reduce the risk of a treatment-related bias, we designed the WBRT-30 score in a cohort of patients with brain metastases who were homogeneously treated with $30 \mathrm{~Gy}$ in 10 fractions of WBRT alone (10). The PPVs of the that WBRT-30 to correctly identify patients dying within 6 months following WBRT (least

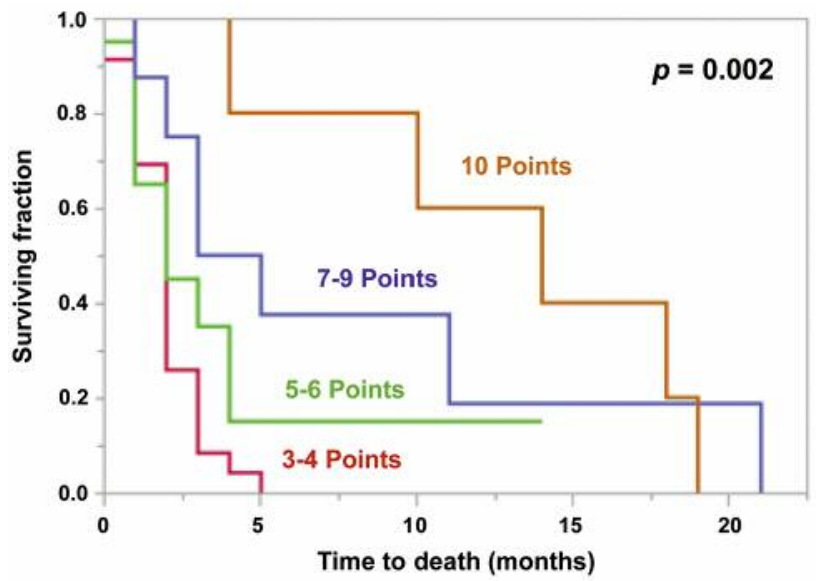

Figure 2. Kaplan-Meier curves of the four prognostic groups (3-4 points, 5-6 points, 7-9 points and 10 points). The p-value was obtained from the log-rank test.

favorable prognostic group) and patients surviving for at least 6 months following WBRT (most favorable group) were 97\% and 96\%, respectively (9). The corresponding PPVs were 92\% and $75 \%$, respectively, when using the RPA classification (7), $96 \%$ and $73 \%$, retrospectively when using our previous score (8), and $85 \%$ and $64 \%$, respectively, when using the GPA classification (9). Thus, the WBRT-30 appeared more precise than the other three scoring systems.

Since each tumor entity is unique with respect to biological behavior, prognoses, and prognostic factors influencing survival, diagnosis-specific GPA classifications were developed for the most common primary tumor types associated with brain metastases including a DS-GPA classification for gastrointestinal cancers (11). The major goal of developing DS-GPA classifications was to achieve a better personalization of treatment than with the general GPA classification. Due to the promising PPVs of the WBRT-30 
in the cohort of patients with brain metastases from different tumor types and the likely better treatment personalization when applying diagnosis-specific scores, the present study was conducted and the specific WBRT-30-CRC score was created for patients with brain metastases from colorectal cancer. This new WBRT-30 score had higher PPVs than the corresponding DS-GPA to correctly predict death within 6 months $(100 \%$ vs. 91\%) or survival for at least 6 months (80\% vs. $0 \%$ or $33 \%$ ) following WBRT (11). Since only one patient had a DS-GPA score of 3.5-4-0 and three patients a DS-GPA score of 3.0-4.0, the validity of the latter comparison must be considered limited.

In the present study, the pairwise comparisons of the different prognostic groups did not achieve significance, which may be explained by the very small numbers of patients in the two groups. Only the comparison of the two largest groups, 3-4 points group and 5-6 points, showed a strong trend. However, the difference between the worst (3-5 points) and the best (10 points) groups was highly significant. Regarding the DS-GPA score, the difference between the largest groups (0-1.0 points and $1.5-2.5$ points) achieved significance, whereas the differences between the other groups were not significant. When comparing the worst and the best prognostic groups, the difference for the WBRT30-CRC was highly significant, whereas in the DS-GPA significance was not reached. This may be considered another argument pro WBRT-30-CRC.

This new WBRT-30-CRC included four prognostic groups with significantly different 6-month survival probabilities. No patient of the 3-4 points group survived 6 months and only 9\% 3 months following WBRT (Figure 2). Therefore, these patients should receive short-course WBRT such as $20 \mathrm{~Gy}$ in 5 fractions or supportive care alone, as suggested in the QUARTZ trial for selected patients with brain metastases from non-small cell lung cancer (19). The 3-month and 6-months survival rates in the 5-6 points group were $35 \%$ and $15 \%$, respectively. These patients are considered good candidates for short-course WBRT. Since in the 7-9 points group, the 3-month and 6-months survival rates were $50 \%$ and $38 \%$, these patients may be treated with $30 \mathrm{~Gy}$ in 10 fractions. Patients achieving 10 points had the most favorable survival prognoses with 3-month and 6month survival rates of $100 \%$ and $80 \%$, respectively. Sixty percent of these patients survived 12 months of longer. Thus, these patients may benefit from longer-course WBRT with higher total doses and lower doses per fractions such as 40 Gy in 20 fractions in terms of improved prognosis with less neurocognitive impairment. For patients of the groups 7-9 points and 10 points, hippocampal sparing should be considered to further reduce the risk of WBRT-related neurocognitive decline. Memantine can also be helpful in preventing cognitive loss in patients who receive whole brain irradiation (13). When following these suggestions, the retrospective nature of the data used for creating the WBRT30-CRC score should be considered, since despite the very homogeneous treatment, a risk of hidden selection biases still exists. Furthermore, the small sample size did not allow an internal validation. However, since the proportion of patients with brain metastases from colorectal cancer who receive WBRT alone is decreasing, also an external validation cannot be expected soon.

In conclusion, this new diagnosis-specific WBRT-30-CRC appeared precise in identifying patients with brain metastases from colorectal cancer dying within 6 months following WBRT and patients surviving for at least 6 months following WBRT. It was developed in a homogeneously-treated patient cohort and, therefore, impacted by the treatment regimen to a lesser extent compared to existing scores. The new WBRT-30-CRC can support physicians when making personalizing therapy.

\section{Conflicts of Interest}

On behalf of all Authors, the corresponding Author states that there is no conflict of interest related to this study.

\section{Authors' Contributions}

D.R., H.C.H., S.J. and S.E.S. participated in the design of the study. D.R., H.C.H. and S.J. provided data. D.R. and S.E.S. performed the analyses and the interpretation of the data. D.R. and S.E.S. drafted the manuscript, which was reviewed and approved in its final form by all Authors.

\section{References}

1 Tsao MN, Rades D, Wirth A, Lo SS, Danielson BL, Gaspar LE, Sperduto PW, Vogelbaum MA, Radawski JD, Wang JZ, Gillin MT, Mohideen N, Hahn CA and Chang EL: Radiotherapeutic and surgical management for newly diagnosed brain metastasis(es): An American Society for Radiation Oncology evidence-based guideline. Pract Radiat Oncol 2: 210-225, 2012. PMID: 25925626. DOI: 10.1016/j.prro.2011.12.004

2 Rades D, Kieckebusch S, Lohynska R, Veninga T, Stalpers LJ, Dunst $\mathrm{J}$ and Schild SE: Reduction of overall treatment time in patients irradiated for more than three brain metastases. Int J Radiat Oncol Biol Phys 69: 1509-1513, 2007. PMID: 17689033.

3 DeAngelis LM, Delattre JY and Posner JB: Radiation-induced dementia in patients cured of brain metastases. Neurology 39: 789-796, 1989. PMID: 2725874.

4 Rades D, Panzner A, Dziggel L, Haatanen T, Lohynska R and Schild SE: Dose-escalation of whole-brain radiotherapy for brain metastasis in patients with a favorable survival prognosis. Cancer 118: 3852-3859, 2012. PMID: 22170514. DOI: 10.1002/ cncr. 26680

5 Gondi V, Tolakanahalli R, Mehta MP, Tewatia D, Rowley H, Kuo JS, Khuntia D and Tomé WA: Hippocampal-sparing wholebrain radiotherapy: a "how-to" technique using helical tomotherapy and linear accelerator-based intensity-modulated radiotherapy. Int J Radiat Oncol Biol Phys 78: 1244-1252, 2010. PMID: 20598457. DOI: 10.1016/j.ijrobp.2010.01.039 
6 Gondi V, Pugh SL, Tome WA, Caine C, Corn B, Kanner A, Rowley H, Kundapur V, DeNittis A, Greenspoon JN, Konski AA, Bauman GS, Shah S, Shi W, Wendland M, Kachnic L and Mehta MP: Preservation of memory with conformal avoidance of the hippocampal neural stem-cell compartment during wholebrain radiotherapy for brain metastases (RTOG 0933): A phase II multi-institutional trial. J Clin Oncol 32: 3810-3816, 2014. PMID: 25349290. DOI: 10.1200/JCO.2014.57.2909

7 Gaspar L, Scott C, Rotman M, Asbell S, Phillips T, Wasserman T, McKenna WG and Byhardt R: Recursive partitioning analysis (RPA) of prognostic factors in three Radiation Therapy Oncology Group (RTOG) brain metastases trials. Int J Radiat Oncol Biol Phys 37: 745-751, 1997. PMID: 9128946.

8 Rades D, Dunst J and Schild SE: A new scoring system to predicting the survival of patients treated with whole-brain radiotherapy for brain metastases. Strahlenther Onkol 184: 251255, 2008. PMID: 18427755. DOI: 10.1007/s00066-008-1831-5

9 Sperduto PW, Berkey B, Gaspar LE, Mehta M and Curran W: A new prognostic index and comparison to three other indices for patients with brain metastases: an analysis of 1,960 patients in the RTOG database. Int J Radiat Oncol Biol Phys 70: 510-514, 2008. PMID: 17931798. DOI: 10.1016/j.jjrobp.2007.06.074

10 Rades D, Dziggel L, Nagy V, Segedin B, Lohynska R, Veninga T, Khoa MT, Trang NT and Schild SE: A new survival score for patients with brain metastases who received whole-brain radiotherapy (WBRT) alone. Radiother Oncol 108: 123-127, 2013. PMID: 23830191. DOI: 10.1016/j.radonc.2013.06.009

11 Sperduto PW, Chao ST, Sneed PK, Luo X, Suh J, Roberge D, Bhatt A, Jensen AW, Brown PD, Shih H, Kirkpatrick J, Schwer A, Gaspar LE, Fiveash JB, Chiang V, Knisely J, Sperduto CM and Mehta M: Diagnosis-specific prognostic factors, indexes, and treatment outcomes for patients with newly diagnosed brain metastases: A multi-institutional analysis of 4,259 patients. Int $\mathbf{J}$ Radiat Oncol Biol Phys 77: 655-661, 2010. PMID: 19942357. DOI: $10.1016 /$ j.ijrobp.2009.08.025

12 Janssen S, Hansen HC, Schild SE and Rades D: An instrument for estimating the 6-month survival probability after whole-brain irradiation alone for cerebral metastases from gynecological cancer. Anticancer Res 38: 3753-3756, 2018. PMID: 29848738. DOI: 10.21873 /anticanres.12656

13 Dziggel L, Gebauer N, Bartscht T, Schild SE and Rades D: Performance status and number of metastatic extra-cerebral sites predict survival after radiotherapy of brain metastases from thyroid cancer. Anticancer Res 38: 2391-2394, 2018. PMID: 29599366. DOI: 10.21873/anticanres.12488
14 Rades D, Dziggel and Schild SE: A specific survival score for patients receiving local therapy for single brain metastasis from a gynecological malignancy. In Vivo 32: 825-828, 2018. PMID: 29936465. DOI: 10.21873/invivo.11314

15 Staackmann C, Janssen S, Schild SE and Rades D: A tool to predict the probability of intracerebral recurrence or new cerebral metastases after whole-brain irradiation in patients with head-and-neck cancer. Anticancer Res 38: 4199-4202, 2018. PMID: 2997055. DOI: 10.21873/anticanres.12714

16 Rades D, Dziggel L, Manig L, Janssen S, Khoa MT, Duong VN, Khiem VH and Schild SE: Predicting survival after whole-brain irradiation for cerebral metastases in patients with cancer of the bladder. In Vivo 32: 633-636, 2018. PMID: 29695570. DOI: 10.21873/invivo.11285

17 Dziggel L, Schild SE, Veninga T, Bajrovic A and Rades D: Clinical factors asssociated with treatment outcomes following whole-brain irradiation in patients with prostate cancer. In Vivo 31: 35-38, 2017. PMID: 28064217. DOI: 10.21873/invivo.11021

18 Brown PD, Pugh S, Laack N, Wefel JS, Khuntia D, Meyers C, Choucair A, Fox S, Suh JH, Roberge D, Kavadi V, Bentzen SM, Mehta MP, Watkins-Bruner D and Radiation Therapy Oncology Group (RTOG): Memantine for the prevention of cognitive dysfunction in patients receiving whole-brain radiotherapy: A randomized, double-blind, placebo-controlled trial. Neuro Oncol 15: 1429-1437, 2013. PMID: 23956241. DOI: 10.1093/ neuonc/not114

19 Mulvenna P, Nankivell M, Barton R, Faivre-Finn C, Wilson P, McColl E, Moore B, Brisbane I, Ardron D, Holt T, Morgan S, Lee C, Waite K, Bayman N, Pugh C, Sydes B, Stephens R, Parmar MK and Langley RE: Dexamethasone and supportive care with or without whole-brain radiotherapy in treating patients with non-small cell lung cancer with brain metastases unsuitable for resection or stereotactic radiotherapy (QUARTZ): results from a phase 3, non-inferiority, randomised trial. Lancet 388: 2004-2014, 2016. PMID: 27604504. DOI: 10.1016/S01406736(16)30825-X 